Address for Correspondence: Prof. Beate Rassler, Carl-LudwigInstitute of Physiology

University of Leipzig, Liebigstr. 27

D-04103 Leipzig, Germany

Email:

beate.rassler@medizin.uni-leipzig.de

\begin{tabular}{|l|}
\hline Access this article online \\
\hline $\begin{array}{l}\text { Website: } \\
\text { www.intern-med.com }\end{array}$ \\
\hline DOI: \\
10.1515/jtim-2015-0022 \\
\hline Quick Response Code: \\
\hline \\
\\
\\
\hline \\
\hline \\
\hline
\end{tabular}

\title{
Increased breathing resistance compromises the time course of rhythmical forearm movements - a pilot study
}

\author{
Ariane Tabary, Beate Rassler \\ Carl-Ludwig-Institute of Physiology, University of Leipzig, Leipzig, Germany
}

\section{ABSTRACT}

Background and Objectives: Skeletal muscle dysfunction is a major problem among the co-morbidities associated with chronic obstructive pulmonary disease (COPD). However, muscle weakness and increased fatigability are not the only limitations of skeletal muscle function. Motor-respiratory coordination (MRC) may occur even during movements at lowest workloads. MRC modifies the temporal pattern of motor actions, thus probably impairing motor performance and movement precision. Little attention has been paid to the question of whether motor functions may be compromised in COPD patients independent of workload and required muscle strength and endurance. The present pilot study was designed to investigate the effects of a simulated obstruction (SO) in healthy subjects on their breathing pattern and the timing of a rhythmical forearm movement. Methods: Twenty-one subjects performed flexionextension movements with their right forearm at a self-chosen rate within a range between 0.2 and $0.4 \mathrm{~Hz}$. After a control experiment with normal breathing, a plug with a narrow hole was inserted between face mask and pneumotachograph to simulate obstruction. Subjects were required to repeat the rhythmical forearm movement at the same rate as in the control experiment. Results: The condition of SO significantly prolonged breath duration but reduced tidal volume and ventilation. In addition, period duration of the forearm movement increased significantly under this condition while the movement-to-breathing frequency ratio remained almost constant. Increased breathing resistance was considered to cause prolonged breath duration accompanied by an increase in movement period duration. The constant near-integer ratio between movement and breathing rates indicates that the change in movement period duration resulted from MRC. Conclusions: The findings of this pilot study demonstrate that increased breathing resistance may compromise motor performance even at lower workloads. This means that in COPD patients, not only muscle strength and endurance are reduced but, moreover, fine motor skills may be impaired. This aspect has particular importance for many everyday activities as reduced fine motor performance substantially contributes to a progressive inability of the patients to manage their daily life.

Key words: motor-respiratory coordination, Simulated obstruction, chronic obstructive pulmonary disease, rhythmical forearm movement, frequency ratio

\section{INTRODUCTION}

Chronic obstructive pulmonary disease (COPD) is one of the most frequent causes of mortality in the world. COPD is usually associated with a number of secondary impairments such as cardiac, metabolic, peripheral muscle, and psychosocial dysfunction. A major problem among these co-morbidities is skeletal muscle dysfunction, which is typically characterized by reduced muscle strength and exercise intolerance. ${ }^{[1-3]}$ Muscular dysfunction in COPD patients mainly concerns the lower $\operatorname{limbs}^{[4]}$, but upper limb muscle function is reduced as well. ${ }^{[5]}$ Reduced muscle strength and endurance significantly deteriorate functional capacity, health-related quality of life, and even mortality in COPD patients. However, muscle weakness and increased fatigability are not the only limitations of skeletal muscle function. 
Voluntary movements, particularly rhythmical limb movements, are often coupled with respiration. Coupling or coordination means modulation of the temporal patterns of both respiration and the additional motor process due to central nervous interactions. Ideally, these interactions result in the adoption of a common rhythm or a stable integer frequency ratio. Motor-respiratory coordination (MRC) can be found during each kind of voluntary motor activity, particularly during rhythmical movements. It typically occurs during locomotion, especially during physical activities at higher workloads such as running, cycling, or rowing. ${ }^{[6-9]}$ However, it has been observed even during fine motor actions at lowest workloads such as hand, finger, head, and eye movements. ${ }^{[10-13]} \mathrm{In} \mathrm{MRC}$, the breathing rhythm is usually influenced by the rhythm of the concomitant movement. ${ }^{[8,9,14,15]}$ However, MRC is a true mutual interaction; this means that the respiratory rhythm can modulate the time course of a non-respiratory movement. ${ }^{[14,16]}$ This may compromise motor performance, particularly in fine motor actions such as precision movements. ${ }^{[17,18]}$ In patients with ventilatory disorders such as COPD, skeletal muscle dysfunction might result not only from reduced muscle strength and endurance but additionally, from impaired motor performance and movement precision due to neural effects from the respiratory rhythm. As precision movements become more and more important both in professional life and in leisure activities (e.g., for using smartphones or computers), those effects might remarkably compromise the patients' daily life.

We designed a study to investigate whether increased effort and workload of breathing due to increased breathing resistance would affect the performance of a simple rhythmical flexion-extension movement of the right forearm. As the workload of this movement is low, reduced working capacity of the muscles is not probable to impair task performance. To have a direct comparison, the experiments were carried out in healthy subjects under normal conditions and under the condition of a simulated obstruction (SO). In this pilot study, we investigated the effects of a transiently increased breathing resistance on the temporal patterns of both breathing and the rhythmical forearm movement. We hypothesized that the increased breathing resistance would affect the time course of breathing and consequently, that of the forearm movement.

\section{METHODS}

\section{Subjects}

Experiments were performed in 21 voluntary healthy subjects (10 females and 11 males, aged $23.5 \pm 4.8$ years). None of them had respiratory, neurological, or motor disorders. All subjects but one were right-handed; the left-handed person regularly used her right hand for writing. Informed consent was obtained from all individual participants prior to the experiment. This study was approved by the local ethics committee and was performed in accordance with the ethical standards laid down in the Declaration of Helsinki.

\section{Experimental set-up}

Subjects were seated at a table looking onto a 17 " monitor (Philips 107E20) at a distance of $70 \mathrm{~cm}$. To guarantee a fixed and comfortable head position, the chin was supported and the forehead was leaned against a horizontal bar. They were instructed to perform rhythmical flexionextension movements with their right forearm at a rate ranging between 0.2 and $0.4 \mathrm{~Hz}$. When subjects put their forearm straight on the table, the angle between the upper $\operatorname{arm}$ and the forearm ranged between $130^{\circ}$ and $150^{\circ}$. Their elbow was supported on a small upholstered pad on the table. The angles between the forearm and the table surface were $18^{\circ}$ in the maximum extended position and $36^{\circ}$ in the maximum flexed position of the forearm movement. The limits of the required movement amplitude were presented on the screen by two horizontal lines. Additionally, the forearm movement was displayed on the monitor.

Forearm movements were measured using a goniometer that was attached to the radial side of the upper arm and the forearm. The goniometer signal was digitalized using DasyLab 3 software (Datalog, Mönchengladbach, Germany). This software also generated the movement signal and the movement limits presented on the screen.

Breathing was recorded using a Fleisch pneumotachograph (G. Hertel, Lengenfeld, Germany). Subjects breathed room air through a face mask. The breathing signal was also digitalized with DasyLab but was not visualized to the subjects.

\section{Study protocol}

At the beginning, subjects were informed in detail on the experimental course, in particular, on the condition of SO. Then, spirometry was conducted twice under normal conditions (CTRL) using a MasterScope PC spirometer (Viasys Healthcare, Hoechberg, Germany). This procedure was repeated under the condition of SO. For this, a plug of $2 \mathrm{~cm}$ of length with a narrow hole with a diameter of $4 \mathrm{~mm}$ was inserted between the face mask and pneumotachograph. We analyzed inspiratory vital capacity (IVC) and forced expiratory volume in $1 \mathrm{~s}\left(\mathrm{FEV}_{1}\right)$. $\mathrm{FEV}_{1}$ measured during $\mathrm{SO}$ served to quantify the effect of the simulation.

After subjects were seated and equipped with measuring facilities, breathing at rest was recorded for 3-4 min under the CTRL condition and thereafter, further 3-4 min under the SO condition. After a 15-30 min interval, subjects performed a pre-test consisting in a visually guided tracking 
procedure with flexion-extension movements of their right forearm for about 5 min under CTRL conditions. Both tracking signal and forearm movement were displayed on the screen as vertical bars in different colors. The tracking signal bar moved upwards and downwards according to a sinus function at a frequency of $0.3 \mathrm{~Hz}$. At this target rate, most stable entrainment patterns with movement-to-breathing frequency ratios of 1:1 have been observed. ${ }^{[15]}$ These tracking tests served to familiarize the subjects with the required movement rate.

In the main experiment, subjects had to perform a similar flexion-extension movement at the same amplitude but without a visual tracking signal. Movement amplitude should be kept exactly in accordance with the limits displayed on the screen. Subjects were instructed to keep the movement rate approximately in the same range as during the pre-test. They did not receive any cues unless their movement rate fell below $0.2 \mathrm{~Hz}$ or exceeded 0.4 $\mathrm{Hz}$. The main experiment consisted of two trials lasting 5-6 min each with a resting interval of $3 \mathrm{~min}$ in between. The first trial was performed under CTRL condition and the second one under the condition of SO. Subjects were instructed to maintain their movement rate and amplitude according to the prior tests.

After completion of the tests, subjects were questioned whether or not they paid attention to their forearm movements and breathing, and whether they felt discomfort with breathing.

\section{Parameters and statistical analysis}

The goniometer signal and the pneumotachogram were digitalized at a sample rate of $100 \mathrm{~Hz}$. The time course of breathing was analyzed breath by breath. We assessed time of inspiration $\left(\mathrm{T}_{\mathrm{i}}\right)$, time of expiration $\left(\mathrm{T}_{\mathrm{e}}\right)$, time of a total breath $\left(\mathrm{T}_{\text {tot }}\right)$, expired tidal volume $\left(\mathrm{V}_{\mathrm{T}}\right)$, and ventilation. For each movement period, we determined time of flexion $\left(\mathrm{T}_{\text {flex }}\right)$, time of extension $\left(\mathrm{T}_{\text {ex }}\right)$, and time of a total period $\left(\mathrm{T}_{\text {move }}\right)$. In addition, we calculated the mean cycle time ratio between movement and breathing (MBCTR).

Results are presented in the text as means \pm SEM. Differences between the conditions were tested for significance using a Wilcoxon matched pairs signed rank test (Statgraphics Plus 4.1 for Windows; Statistical Graphics Corporation, Rockville, Maryland, USA). $P$-values less than 0.05 were considered to be significant.

\section{RESULTS}

\section{Spirometry}

All subjects presented with normal lung function. IVC was $4.76 \pm 0.21 \mathrm{~L}\left(102 \%\right.$ of predicted value) and $\mathrm{FEV}_{1}$ was
$4.08 \pm 0.17 \mathrm{~L}$ (106\% of predicted value). Relative $\mathrm{FEV}_{1}$ was $86.2 \%$ of IVC. While IVC was almost unaffected by SO ( $101 \%$ of predicted value), $\mathrm{FEV}_{1}$ was reduced by $53 \%$ of CTRL ( $55 \%$ of predicted value, $P=4 * 10^{-10} ; 45.3 \%$ of IVC). Thus, our simulation corresponded to a moderate degree of obstruction according to the GOLD classification of airflow limitation in COPD. ${ }^{[19]}$

\section{Breathing at rest}

In the resting CTRL condition, breathing rate was 15.7 breaths per min $\left(\mathrm{T}_{\text {tot }}=3.82 \pm 0.21 \mathrm{~s}\right)$ on average, with $\mathrm{T}_{\mathrm{i}}$ and $\mathrm{T}_{\mathrm{e}}$ being $1.56 \pm 0.08 \mathrm{~s}$ and $2.23 \pm 0.13 \mathrm{~s}$, respectively. Tidal volume was $0.59 \pm 0.03 \mathrm{~L}$ and ventilation was 9.46 $\pm 0.32 \mathrm{~L} / \mathrm{min}$. SO induced a significant prolongation of breath duration $\left(\mathrm{T}_{\text {tot }}=4.17 \pm 0.2 \mathrm{~s}, P=0.047\right)$ that was mainly based on an increase in $\mathrm{T}_{\mathrm{i}}(1.74 \pm 0.09 \mathrm{~s}, P=0.015)$. This was associated with a significant reduction in $\mathrm{V}_{\mathrm{T}}(0.53$ $\pm 0.03 \mathrm{~L}, P=0.002)$ and ventilation $(7.60 \pm 0.30 \mathrm{~L} / \mathrm{min}, P$ $\left.=7 * 10^{-5}\right)$; see Figure 1 .

\section{Breathing during rhythmical forearm movement}

In the movement experiment, breathing rate and $\mathrm{V}_{\mathrm{T}}$ increased slightly to 16.6 breaths per minute and $0.61 \pm 0.03 \mathrm{~L}$ in the CTRL condition. Breath duration decreased to $3.61 \pm 0.14$ $\mathrm{s}$ with $\mathrm{T}_{\mathrm{i}}=1.50 \pm 0.06 \mathrm{~s}$ and $\mathrm{T}_{\mathrm{e}}=2.10 \pm 0.09 \mathrm{~s}$. Although these changes were not significant, ventilation was significantly higher than at rest $(10.19 \pm 0.36 \mathrm{~L} / \mathrm{min}, P=0.005)$.

However, in the SO condition, no change in the breathing pattern occurred while movements were performed. Consequently, with SO breath duration was longer $\left(\mathrm{T}_{i}=\right.$ $1.74 \pm 0.08 \mathrm{~s}, P=0.0003 ; \mathrm{T}_{\mathrm{e}}=2.35 \pm 0.12 \mathrm{~s}, P=0.006$; $\left.\mathrm{T}_{\text {tot }}=4.14 \pm 0.19 \mathrm{~s}, P=0.002\right)$ and $\mathrm{V}_{\mathrm{T}}$ and ventilation were lower $(0.55 \pm 0.03 \mathrm{~L}, P=0.003$ and $7.97 \pm 0.29 \mathrm{~L} / \mathrm{min}, P=$ $9 * 10^{-5}$, respectively) than in the CTRL condition (Figure 1).

\section{Temporal pattern of forearm movement and MBCTR}

In the CTRL condition, the average movement period $\mathrm{T}_{\text {move }}$ was $3.70 \pm 0.12 \mathrm{~s}$. Durations of flexion and extension periods were almost equal $\left(\mathrm{T}_{\text {flex }}=1.88 \pm 0.06 \mathrm{~s} ; \mathrm{T}_{\mathrm{ext}}=1.82\right.$ $\pm 0.07 \mathrm{~s})$. MBCTR was $1.06 \pm 0.06$. In SO, movement period was significantly longer with $\mathrm{T}_{\text {move }}=3.93 \pm 0.11 \mathrm{~s}$ $(P=0.039)$. This was mainly due to an increase in $\mathrm{T}_{\text {flex }}$ to $2.02 \pm 0.06 \mathrm{~s}(P=0.024)$ while the extension period was less prolonged ( $\left.\mathrm{T}_{\mathrm{ext}}=1.91 \pm 0.06 \mathrm{~s} ; P=0.034\right)$; see Figure 2 . Consequently to this prolongation in $\mathrm{T}_{\text {move }}$, MBCTR was maintained at $0.99 \pm 0.06$.

In the final interview, 14 subjects stated that they had noticed to adopt a common rhythm between forearm movement and breathing. Four of them inhaled with flexion and exhaled during forearm extension; the others did not specify the phase relation. 

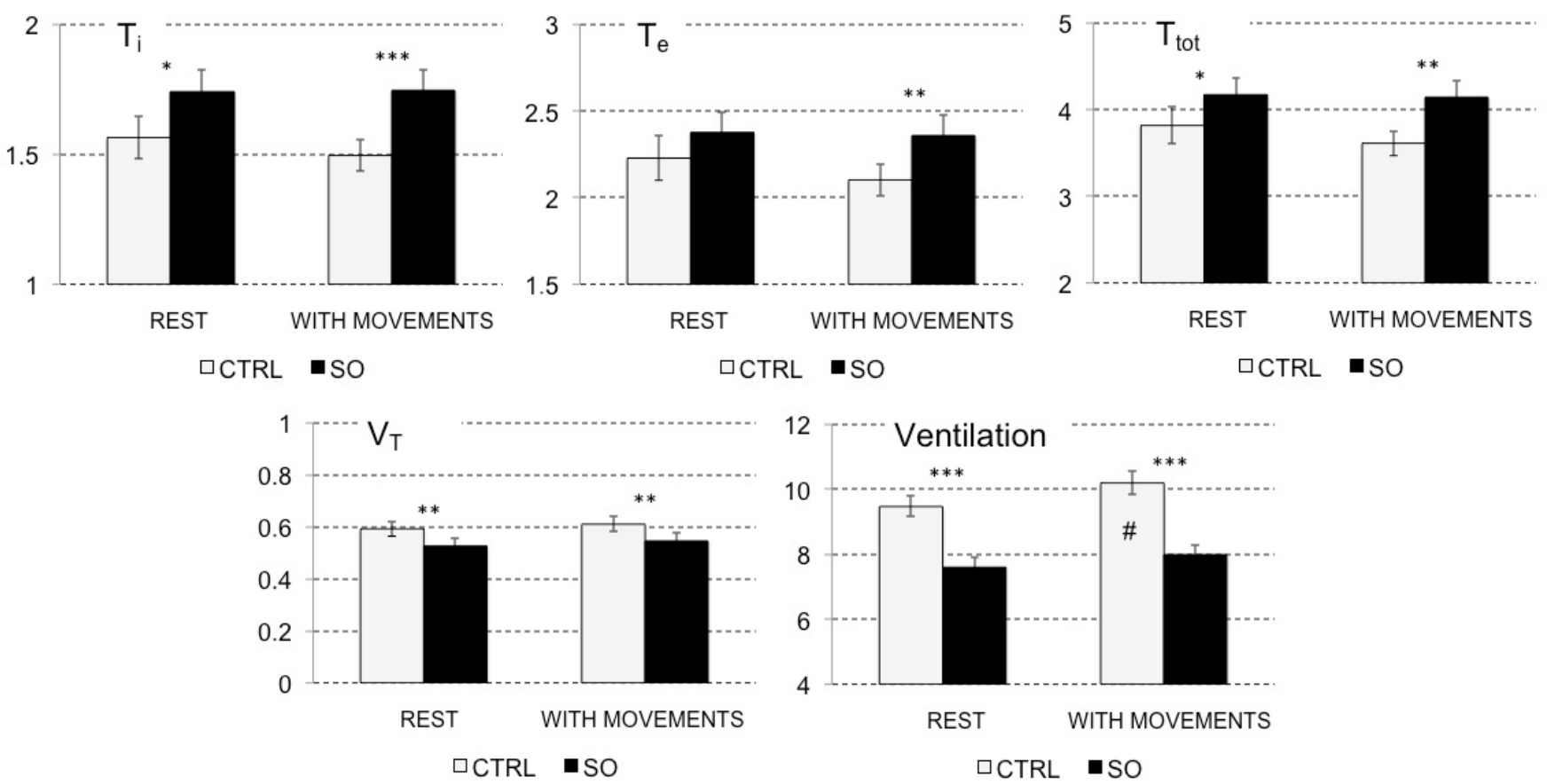

Figure 1: Breathing parameters at rest (left columns) and during rhythmical forearm movements (right columns) in the control condition (CTRL, grey columns) and in the condition of simulated obstruction ( $\mathrm{SO}$, black columns): time of inspiration $\left(\mathrm{T}_{\mathrm{j}}\right)$, time of expiration $\left(\mathrm{T}_{\mathrm{e}}\right)$, time of a total breath $\left(\mathrm{T}_{\text {tot }}\right.$ ), expired tidal volume $\left(\mathrm{V}_{\mathrm{T}}\right)$, and ventilation. Asterisks mark significant differences between CTRL and S0: ${ }^{*} P<0.05$; ${ }^{*} P<0.01$; ${ }^{* *} P<0.001$. \# marks a significant difference from the corresponding condition at rest.
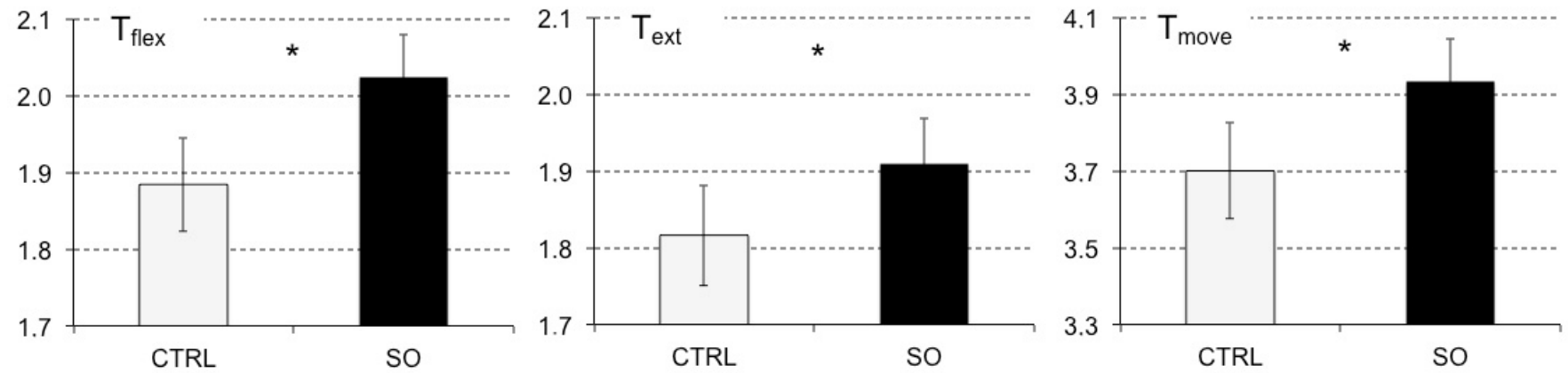

Figure 2: Movement parameters in the control condition (CTRL, grey columns) and in the condition of simulated obstruction (SO, black columns): time of flexion (T flex $_{\text {t }}$ time of extension $\left(\mathrm{T}_{\text {ext }}\right)$, and time of a total movement cycle $\left(\mathrm{T}_{\text {move }}\right)$. Asterisks mark significant differences between $\mathrm{CTRL}$ and $\mathrm{S} 0:{ }^{*} P<0.05$.

\section{DISCUSSION}

The main finding of this pilot study was that simulation of moderate obstruction modulated the temporal pattern of a rhythmical forearm movement performed without any additional workload. Although subjects were instructed to move their forearm in the same rhythm as they did just before under CTRL condition, their movement was slowed down in the SO condition.

Increased breathing resistance is a typical feature of advanced COPD. While the normal pulmonary resistance is about $1 \mathrm{~cm} \mathrm{H}_{2} \mathrm{O} \mathrm{L}^{-1}$, it can increase in COPD to 5-15 $\mathrm{cm} \mathrm{H}_{2} \mathrm{O} \mathrm{L}^{-1}$ and more. ${ }^{[20,21]}$ Roughly calculated, increasing the inspiratory resistance by 10 -fold during breathing at rest would increase the resistive work of breathing also by about 10-fold. ${ }^{[2]}$ Our subjects reported that they felt discomfort and greater effort of breathing in the SO condition. Due to the elevated inspiratory resistance in this condition, they reduced their tidal volume and prolonged their breaths by about $10 \%$ even in the absence of any additional activity.

The start of the forearm movement was accompanied by a slight increase in breathing rate by about 6\% in the CTRL condition. This increase in breathing rate confirms previous findings with finger movements. ${ }^{[17,23]}$ It reflects the increased respiratory drive resulting from activation of motor centers. In the $\mathrm{SO}$ condition, no change in the breathing pattern was observed with the start of the movements. We assume that the increased respiratory work due to the elevated breathing 
resistance was an additional drive to breathing exceeding that from motor control. A previous study with finger tracking movements under hypercapnic conditions showed that at the onset of movement, breathing rate increased only half as much as under normocapnic conditions. ${ }^{[24]}$

Although subjects were instructed to perform the rhythmical forearm movement both in the CTRL and in the $\mathrm{SO}$ condition at the same rate, their movement rate was lower in the SO condition. It is well documented that resistive loaded breathing can modulate the electromyogram pattern of limb muscles in a differential way. ${ }^{[25-27]}$ Inspiratory resistive loading significantly prolonged latencies in somatosensory evoked potentials of the median nerve in humans. ${ }^{[2]}$ These effects are discussed to result from respiratory afferent activation. ${ }^{[27]}$ Central respiratory activation by increased respiratory drive also modulates the temporal pattern of motor functions. We observed that hypercapnia increased the latency of finger tracking movements, predominantly during expiration. ${ }^{[24]}$ These findings suggest that increased breathing resistance may amplify neural effects from respiration onto the rhythm of a non-respiratory movement.

During rhythmic movements, subjects often adopt integer movement-to-breathing rate ratios. Stable 1:1 ratios frequently occur at movement rates near the normal breathing rate. ${ }^{[14,15]}$ These rate ratios are considered to result from MRC. With rhythmical forearm tracking movements, 1:1 coordination was observed between 0.2 and $0.6 \mathrm{~Hz}$ with a maximum at $0.3 \mathrm{~Hz}$. Within this range, breathing rate increased with the movement rate, though maintenance of a 1:1 rate ratio became more and more unstable. At higher movement rates, however, breathing rate did not further increase but coordination switched to higher integer ratios such as 2:1, 3:1, and more. ${ }^{[15]}$ Modulation of the respiratory time course by additional motor activities is typical, but there are also effects in the opposite direction. In walking, modulation of the stepping rate by the breathing rhythm has been observed in periods of MRC, particularly when the variability of breathing was restricted by acoustic pacing of the respiratory rhythm. ${ }^{[16]}$ We assume that in the SO condition, variability of the respiratory rhythm has been reduced by the additional breathing effort. This might help to reduce discomfort of breathing, to avoid further inefficiency of breathing, and to ensure adequate gas exchange. The respiratory rhythm, in turn, slowed down the rhythm of the forearm movement so that the 1:1 rate ratio was maintained. The majority of subjects noticed that their breathing and movement rhythms were equal but most of them did not clearly state which phases of forearm movement and breathing were coupled to each other.
Coordination is associated with the adoption of a certain phase relationship, which often consists in the coincidence of so-called "anchor points," that is, points of maximum angular excursion. ${ }^{[29]}$ In MRC, the start of a movement phase preferably coincides with the start of inspiration or expiration. ${ }^{[8,10,11,14,18,30]}$ In a recent study with rhythmical forearm tracking movements, we found coincidence of the start of flexion with the start of expiration. ${ }^{[31]}$ These coincidences result from a periodically varying interaction between the processes. When subjects started a single finger movement in the first half of inspiration or expiration, they performed it faster and more precisely than a movement started late in inspiration or expiration. ${ }^{[17]}$ Likewise, breath duration was modulated in a phase-dependent manner: When the finger movement started early in inspiration, both the current inspiration and the related expiration were shortened. In contrast, when the movement started late in expiration, duration of the current expiration did not change or even increase but the subsequent breath was shortened. ${ }^{[17,24]}$ These phase-dependent differences were even more pronounced in hypercapnia ${ }^{[2]}$ indicating that MRC became stronger with increased respiratory drive. This may also count for the changes in breathing and movement duration observed in the present study with increased breathing resistance.

\section{CONCLUSION}

The findings of the present study clearly demonstrate that MRC can considerably modulate the temporal patterns of both respiration and non-respiratory movements. With increased respiratory resistance such as in COPD patients, these interactions are even stronger than under normal respiratory conditions. This may particularly impair fine motor skills and thus, significantly compromise the daily life of COPD patients.

\section{Acknowledgments}

We gratefully acknowledge the valuable conceptual and methodological comments of Prof. Siegfried Waurick and Dr. Dietrich Ebert. We thank Mr. Bengt Bartsch and Mrs. Veronika Bieber for their technical assistance.

\section{Conflict of Interest}

The authors declare that they have no conflict of interest.

\section{REFERENCES}

1. Gosselink R, Troosters T, Decramer M. Peripheral muscle weakness contributes to exercise limitation in COPD. Am J Respir Crit Care Med 1996;153:976-80.

2. Clark CJ, Cochrane LM, Mackay E, Paton B. Skeletal muscle strength and endurance in patients with mild COPD and the effects of weight training. Eur Respir J 2000;15:92-7. 
3. Debigaré R, Maltais $\mathrm{F}$. The major limitation to exercise performance in COPD is lower limb muscle dysfunction. J Appl Physiol 2008; 105: 751-3.

4. Donaldson AV, Maddocks M, Martolini D, Polkey MI, Man WD-C. Muscle function in COPD: a complex interplay. Int J COPD 2012; 7: 523-35.

5. Shah S, Nahar P, Vaidya S, Salvi S. Upper limb muscle strength and endurance in chronic obstructive pulmonary disease. Indian J Med Res 2013; 138: 492-6.

6. McDermott WJ, Van Emmerik RE, Hamill J. Running training and adaptive strategies of locomotor-respiratory coordination. Eur J Appl Physiol 2003; 89:435-44.

7. Bernasconi P, Kohl J. Analysis of co-ordination between breathing and exercise rhythms in man. J Physiol (London) 1993; 471: 693-706.

8. Kohl J, Koller EA, Jäger M. Relation between pedalling- and breathing rhythm. Eur J Appl Physiol Occup Physiol 1981; 47: 223-37.

9. Siegmund GP, Edwards MR, Moore KS, Tiessen DA, Sanderson DJ, McKenzie DC. Ventilation and locomotion coupling in varsity male rowers. J Appl Physiol 1999; 87:233-42.

10. Temprado JJ, Milliex L, Grélot L, Coyle T, Calvin S, Laurent M. A dynamic pattern analysis of coordination between breathing and rhythmic arm movements in humans. Neurosci Lett 2002; 329:314-8.

11. Wilke JT, Lansing RW, Rogers CA. Entrainment of respiration to repetitive finger tapping. Physiol Psychol 1975;3:345-9.

12. Waurick $S$. The influence of eyetracking movements on the breathing pattern of men. In: Seliger V (editor) Physical Fitness. UniversitaKarlova, Prague1973, pp 443-448.

13. Rassler B, Raabe J. Co-ordination of breathing with rhythmic head and eye movements and with passive turnings of the body. Eur J Appl Physiol 2003; 90:125-30.

14. Rassler B, Waurick S, Ebert D. Einfluß zentralnervöser Koordination im Sinne v. Holsts auf die Steuerung von Atem- und Extremitätenmotorik des Menschen. Biol Cybern 1990; 63:457-62.

15. Ebert D, Rassler B, Hefter H. Coordination between breathing and forearm movements during sinusoidal tracking. Eur J Appl Physiol 2000; 81:288-96.

16. Rassler B, Kohl J. Coordination-related changes in the rhythms of breathing and walking in humans. Eur J Appl Physiol 2000; 82:280-8.

17. Rassler B, Ebert D, Waurick S, Junghans R. Coordination Between Breathing and Finger Tracking in Man. J Mot Behav 1996; 28:48-56.

18. Rassler B. Mutual nervous influences between breathing and precision finger movements. Eur J Appl Physiol 2000; 81:479-85.

19. Global Initiative for Chronic Obstructive Lung Disease (GOLD): Global strategy for the diagnosis, management, and prevention of chronic obstructive pulmonary disease - updated 2015. Available at: http://www.
goldcopd.org/uploads/users/files/GOLD_Report_2015_Apr2.pdf (Accessed on 2 November, 2015).

20. Chiang ST, Green J, Wang WF, Yang YJ, Shiao M, King SC. Measurements of components of resistance to breathing. Chest 1989;96:307-11.

21. Ingenito EP, Evans RB, Loring SH, Kaczka DW, Rodenhouse JD, Body $\mathrm{SC}$, et al. Relation between preoperative inspiratory lung resistance and the outcome of lung-volume-reduction surgery for emphysema. N Engl J Med 1998;338:1181-5.

22. Loring SH, Garcia-Jacques M, Malhotra A. Pulmonary characteristics in COPD and mechanisms of increased work of breathing. J Appl Physiol 2009; 107: 309-14.

23. Rassler B, Bradl U, Scholle HC. Interactions of breathing with the postural regulation of the fingers. Clin Neurophysiol 2000; 111: 2180-7.

24. Rassler B, Nietzold I, Waurick S. Phase-dependence of breathing and finger tracking movements during normocapnia and hypercapnia. Eur J Appl Physiol Occup Physiol 1999; 80:324-32.

25. Fontanari P, Vuillon-Cacciuttolo G, Balzamo E, Zattara-Hartmann MC, Lagier- Tessonnier F, Jammes Y. Resistive loaded breathing changes the motor drive to arm and leg muscles in man. Neurosci Lett 1996;210:130-4.

26. Turner D, Sumners P, Jackson S. Changes in electromyogram during upper limb muscle contraction induced by resistive loaded breathing in humans. Neurosci Lett 2000; 296: 45-8.

27. Turner D, Jackson S. Resistive loaded breathing has a functional impact on maximal voluntary contractions in humans. Neurosci Lett 2002;326:77-80.

28. Balzamo E, Pellegrin V, Somma-Mauvais H, Jammes Y. Activation of respiratory afferents by resistive loaded breathing modifies somatosensory evoked potentials to median nerve stimulation in humans. Neurosci Lett 1999;270:157-60.

29. Byblow WD, Carson RG, Goodman D. Expressions of asymmetries and anchoring in bimanual coordination. Human Movement Science 1994;13:3-28.

30. Amazeen PG, Amazeen EL, Beek PJ. Coupling of breathing and movement during manual wheelchair propulsion. J Exp Psychol Hum Percept Perform 2001;27:1243-59.

31. Krupnik V, Nietzold I, Bartsch B, Rassler B. The effect of motor-respiratory coordination on the precision of tracking movements: influence of attention, task complexity and training. Eur J Appl Physiol 2015; DOI 10.1007/s00421-015-3250-5.

How to cite this article: Tabary A, Rassler B. Increased breathing resistance compromises the time course of rhythmical forearm movements—a pilot study. J Transl Intern Med 2015; 3: 161-166. 